TI 2011-108/3

Tinbergen Institute Discussion Paper

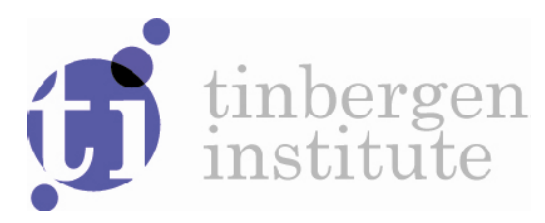

\title{
Free Medicines thanks to Retirement: Moral Hazard and Hospitalization Offsets in an NHS
}

\author{
Jaume Puig-Junoya \\ Pilar García-Gómezb \\ David Casado-Marínc
}

a Department of Economics and Business, Universitat Pompeu Fabra, and Research Centre for Economics and Health (CRES), Barcelona, Spain;

${ }^{b}$ Department of Applied Economics, Erasmus School of Economics, Erasmus University Rotterdam, Rotterdam, The Netherlands;

c Institut d'Avaluació de Polítiques Públiques (IVALUA), Barcelona, Spain. 
Tinbergen Institute is the graduate school and research institute in economics of Erasmus University Rotterdam, the University of Amsterdam and VU University Amsterdam.

More TI discussion papers can be downloaded at http://www.tinbergen.nl

Tinbergen Institute has two locations:

Tinbergen Institute Amsterdam

Gustav Mahlerplein 117

1082 MS Amsterdam

The Netherlands

Tel.: +31(0)205251600

Tinbergen Institute Rotterdam

Burg. Oudlaan 50

3062 PA Rotterdam

The Netherlands

Tel.: +31(0)10 4088900

Fax: $+31(0) 104089031$

Duisenberg school of finance is a collaboration of the Dutch financial sector and universities, with the ambition to support innovative research and offer top quality academic education in core areas of finance.

DSF research papers can be downloaded at: http://www.dsf.nl/

Duisenberg school of finance

Gustav Mahlerplein 117

1082 MS Amsterdam

The Netherlands

Tel.: +31(0)20 5258579 


\title{
FREE MEDICINES THANKS TO RETIREMENT: MORAL HAZARD AND HOSPITALIZATION OFFSETS IN AN NHS
}

\author{
JAUME PUIG-JUNOY ( $\left.{ }^{\mathrm{a},}{ }^{*}\right)$, PILAR GARCÍA-GÓMEZ ( $\left.{ }^{\mathrm{b}}\right)$, and DAVID CASADO- \\ MARÍN (')
}

(a) Department of Economics and Business, Universitat Pompen Fabra, and Research Centre for Economics and Health (CRES), Barcelona, Spain

(b) Department of Applied Economics, Erasmus School of Economics, Erasmus University Rotterdam, the Netherlands. Tinbergen Institute, the Netherlands. NETSPAR, the Netherlands

(c) Institut d'Avaluació de Politiques Públiques (IV ALUA), Barcelona, Spain

\begin{abstract}
This paper examines the impact of coinsurance exemption for prescription medicines applied to elderly individuals in Spain after retirement. To evaluate this coinsurance change we use a rich administrative dataset that links pharmaceutical consumption and hospital discharge records for the full population aged 58 to 65 in January 2004 covered by the public insurer in a Spanish region and we follow them until December 2006. We use a difference-in-differences strategy and exploit the eligibility age for Social Security to control for the endogeneity of the retirement decision. Our most conservative results show that the uniform exemption from pharmaceutical copayment granted to retired people in Spain increases the consumption of prescription medicines on average by $9.5 \%$, total pharmaceutical expenditure by $15.2 \%$ and the costs borne by the insurer by $47.5 \%$, without evidence of any offset effect in the form of reduced hospitalization. The impact is concentrated among individuals who were consumers of medicines for acute and other non-chronic diseases with a previous coinsurance rate in the range $30 \%$ to $40 \%$.
\end{abstract}

Key words: pharmaceuticals; cost sharing; hospitalization offsets; health care expenditure.

JEL codes: G22, I18, J14

(*) Correspondence to: Research Centre for Economics and Health, C/ Trias Fargas 25-27, 34-08005 Barcelona, Spain. Tel.: +34 93542 1857. Fax: +34 93542 1746. E-mail: jaume.puig@upf.edu.

Acknowledgements: This study was supported by an unrestricted educational grant from the Merck Foundation, the philanthropic arm of Merck \& Co. Inc., Whitehouse Station, New Jersey, USA. Partial funding was also obtained from the Spanish Ministry of Science and Education under grant SEJ2007-66133, and the Department of Health of the Government of Catalonia. Pilar García-Gómez thankfully acknowledges financial support from the European Union under the Marie Curie Intra-European Fellowships. 


\section{INTRODUCTION}

Over the past four decades, all developed countries have been struggling with the rise in government and private health expenditure, which have increased in most countries faster than GDP. The recent economic recession has reduced government revenues, increasing the pressure to control costs. However, the experience of previous recessions in countries which reduced health expenditure shows that such reductions were short-lived and after a short period demand for health services increased expenditure (Scherer and Devaux, 2010). When there is severe pressure to reduce public spending there is a growing need to reduce less effective and less cost-effective services in order to secure best value for money and to implement long-lived and financially sustainable policies limiting spending without compromising gains in health outcomes.

Pharmaceutical spending accounts for a significant and increasing proportion of total health care costs in developed countries. Over the last decade, public and private insurers have intensified their efforts to slow down pharmaceutical expenditure growth through a mix of price regulation and volume controls targeted towards the pharmaceutical industry, physicians and pharmacies, as well as increasing the share of the cost borne by users. Pharmaceuticals are typically covered with less generosity than other health care services in nearly all OECD countries (OECD, 2010).

Despite the widespread use of cost sharing arrangements to finance pharmaceuticals, in many countries the actual level of out-of-pocket expenses for covered medicines is undermined by population-wide and generous exemptions from these cost sharing arrangements. In 2008-9, out of 29 OECD countries, 24 countries exempted from cost sharing those individuals with specific medical conditions and disabilities, 13 countries exempted seniors, and 13 countries exempted pregnant women (Paris et al, 2010). Therefore, the exemption affects those patients that concentrate most of the pharmaceutical consumption. This leads to formal cost sharing to be applied to a very meagre proportion of overall pharmaceutical consumption. The result is that the effective role of patient cost sharing as a demand-side strategy to reduce overconsumption and services with low effectiveness in predominantly publicly financed health care systems is restricted to a small pharmaceutical market share, especially in the 13 OECD countries 
where exemptions are leading to free or nearly free prescription medicines for all elderly people.

Despite the widespread use of exemption programmes, there is a surprising scarcity of economic evidence on moral hazard effects for free prescription medicines in the context of national health service (NHS) systems. This is especially so regarding changes in behaviour due to the change in the cost sharing arrangement when elderly people become eligible for the exemption for receiving prescription medicines under insurance coverage. Also, there is hardly any evidence on the existence of substitution effects on ambulatory and inpatient hospital care and health effects in NHS systems. An offset effect could be hypothesized to exist for elderly patients in the form of reduced hospital utilization when they become eligible for high cost sharing exemption. This offset effect may arise from increased initiation of chronic treatment or improved patient compliance for effective prescription medicines under free care.

In this paper we examine the important change in cost sharing for prescription medicines that takes place in the Spanish National Health Service for elderly patients after retirement. When Spaniards transit into retirement, they are exempted from the previous high coinsurance rate for prescription medicines and get complete free access to prescription medicines for them and all their dependants. To evaluate this coinsurance change we use a rich administrative dataset that links pharmaceutical consumption and hospital discharge records for the full population aged 58 to 65 in January 2004 covered by the public insurer in a Spanish region. Following them until December 2006, we compare consumption trends of individuals who transit into retirement with those of individuals whose exemption status does not change and exploit the institutional features of the Spanish Social Security System to instrument the retirement decision in an instrumental variables fixed effects estimation.

We find that this change in cost sharing has strong effects on both consumption and total pharmaceutical expenditure. Our most conservative estimates show that pharmaceutical consumption (measured as the number of DDDs) increases by $9.5 \%$ due to copayment exemption and total pharmaceutical expenditures by $15.2 \%$. The effect on the public insurer is larger as it includes not only the increase in pharmaceutical consumption but also a cost shift from the patient to the insurer due to the exemption. Therefore, we find that 
the costs of the public insurer increase by $47.5 \%$ due to copayment exemption. On the other hand, there are no significant effects on the probability of hospitalization and the number of hospital nights. This suggests that there are no potential offset effects. In addition, the analysis of the heterogeneity of the effects reveals that the moral hazard is concentrated among individuals who were consumers of acute and other non-chronic diseases with a previous coinsurance rate in the range 30\% to $40 \%$. Furthermore, the absence of offset effects remains in all the different subgroups.

This paper is structured as follows. Section 2 provides some background on previous work in this area and on the policy we are studying. Section 3 describes the data and empirical strategy. Section 4 presents our results on price sensitivity and hospitalization offset for the average patient and provides evidence of the heterogeneity of the results. The paper concludes with a summary of the main conclusions and the discussion of the policy implications.

\section{BACKGROUND}

\subsection{Previous studies}

The Rand Health Insurance Experiment (HIE), a large randomized social experiment performed in the United States from 1974 to 1982, provided evidence on the sensitivity of pharmaceutical expenditure and health care use to its own price for the non-elderly when simultaneous similar copayment rates with an income-related cap are applied to all health services (Newhouse, 1993). Average expenditure on prescription medicines of consumers in the least generous plan were $57 \%$ of those on a free plan. The plan response for prescription medicines was similar to that of total outpatient care (Leibowitz et al, 1985). The arc elasticity for outpatient care was -0.13 for nominal coinsurance rates in the range 0 25\%, and -0.21 for nominal rates between 25 and 95\% (Manning et al, 1987). Free care appears to increase both appropriate and inappropriate use of antibiotics. However, no adverse effects on health were found to be associated with cost sharing, except that free care led to improvements in hypertension, dental health, vision, and selected serious symptoms. 
Nowadays, despite its random nature, the usefulness of the Rand HIE for the design of optimal pharmaceutical cost sharing is limited for three main reasons. First, it is more than three decades old and since then there has been a notable increase in cost and extension of treatment possibilities in all health systems, especially in pharmaceutical treatments. Second, elderly people, who in many countries are responsible for more than three quarters of the pharmaceutical expenditure, were excluded from the randomized experiment. And, third, the HIE does not allow us to disentangle the adverse offset effects of pharmaceutical cost sharing from those stemming from copayment on other health services.

More recently, Chandra et al (2010) estimated modest but significant price sensitivity for both physician visits and prescription drug consumption among the elderly Medicare population in California, United States. They evaluated the effects of a simultaneous increase in patient cost sharing for physician visits and medicines, which did not allow them to disentangle changes in the level of pharmaceutical copayment from those of visit copayments as individual contributors to the offset effect observed in the form of increased hospital utilization in response to higher copayments by the most ill populations. Natural experiments and quasi-experimental designs for radical changes in cost sharing arrangements such as their indiscriminate abolition through exemption for all elderly people in NHS systems, where most other health services are free of charge, are rare or non-existent. Existing studies are not only scarce, but of limited design quality, and they do not explicitly address heterogeneity in the magnitude of the impact, the own-price elasticity, and whether free access to medicines for the elderly causes an offset in the form of reduced medical costs in other health services, and the presumable improvement in their health outcomes.

Many previous cost sharing studies that focused on drug copayment impact on the elderly populations are simple cross-section or before/after comparisons without a control group (Rice and Matsuoka, 2004; Goldman et al, 2007). A survey of this literature, mainly based on the US and Canada, reports that increasing prescription cost sharing is not only associated with lower rates of drug treatment, but with worse adherence and therapy discontinuation (Goldman et al, 2007).

Recent non-US based studies on the impact of pharmaceutical copayment using individual data on the elderly population are relatively few and have not produced irrefutable evidence 
on its magnitude or price sensitivity. Grootendorst (1997), using a fixed-random effects model without a control group, finds that eligibility for zero copayment of British Columbia residents aged 65 or over living in single person households has a minor contribution to overall expenditure increase compared with trend effects. Atella et al (2006) argue that Italian hypertensive patients treated with ACE inhibitors strongly reduce compliance after copayment increases, which leads to increases in hospitalization and mortality rates. The latter effect is obtained by comparing compliers with non-compliers. This may not reflect the behaviour of those who have been affected by copayment changes.

\subsection{Institutional setting}

The Spanish National Health System (NHS) provides generous free health care coverage to all Spanish residents, except civil servants, with the exception of a non-refundable coinsurance rate for outpatient prescription pharmaceuticals, which has remained at $40 \%$ of the retail price since the early 1980s. A lower coinsurance rate of $10 \%$ is applied to AIDS patients and to medicines mainly prescribed for chronic diseases, with a price cap of $€ 2.64$ per prescription. Thus, effective coinsurance rates for insured patients may range from $40 \%$ to a rate slightly above zero for highly priced medicines under the lower coinsurance rate. In addition, drugs provided to hospitalized patients are provided free of charge.

Pensioners and their dependants are exempted from this coinsurance scheme, so those coinsurance rates are applied only to active people and their dependants, independently of their socio-economic characteristics. Caps or ceilings on maximum out-of-pocket expenditure do not exist either. Active individuals who transit into retirement or receive an incapacity pension, independently of their age, and all their dependants are automatically exempted from the pharmaceutical coinsurance scheme and get free access to outpatient prescription medicines (Costa-Font and Puig-Junoy, 2007).

Nominal coinsurance rates $(40 \%$ and $10 \%)$ have remained unchanged in the last two decades although the effective average coinsurance rate has halved since the eighties (from $15 \%$ in 1980 to $7 \%$ in 2009). The reduction in effective cost sharing might be explained by the increasing ageing process, a larger number of medicines with a $10 \%$ coinsurance rate, 
and the fact that pensioners often may be obtaining prescriptions for other household members who are not exempt from copayments (Puig-Junoy, 1988).

Our analysis focuses on the exemption from the current coinsurance scheme for the outpatient prescription medicines of retired people in Spain. We are interested in the change in consumption due to the change in the coinsurance rate among those insured individuals who were cost sharing and become exempted from the coinsurance (zero price) after retirement.

\section{DATA AND EMPIRICAL STRATEGY}

\subsection{Data}

We use an administrative database of pharmaceutical and inpatient care utilization containing all the population aged 58 to 64 who were covered by the public insurer in Catalonia on 1 January 2004 and were still alive on 31 December 2006 (447,888 individuals). We observe for each individual over the period 2004-2006 monthly pharmaceutical consumption prescribed by a Spanish NHS doctor. The resulting dataset includes individual information on the monthly number of prescriptions, the number of prescribed daily defined doses (DDD) ${ }^{1}$, total pharmaceutical expenditure, pharmaceutical costs borne by the individual, number of prescriptions, and average retail price per prescription.

We select the sample of continuously insured individuals with positive pharmaceutical consumption in each of the three years of the study. By restricting the sample to the subgroup of consumers, we minimize the effects that an increase in the amount of leisure time associated with retirement may have on the probability of visiting a doctor to get the prescription for those individuals who were previously buying their medicines from the

\footnotetext{
${ }^{1}$ A DDD is defined as the average daily dose of an NCE used by an adult for treatment of the main indication of the pharmaceutical.
} 
pharmacy without a prescription (236,992 individuals, representing $53 \%$ of the insured population).

We are interested in the causal effect of the exemption from the coinsurance scheme on total pharmaceutical consumption and expenditure (valued at retail prices), and on inpatient care utilization. Therefore, we analyse the effects of the coinsurance exemption on the following three pharmaceutical outcome variables: number of defined daily doses (DDD), total expenditure and cost borne by the public insurance. We also analyse two hospital utilization outcome variables: whether the individual spent any days in the hospital during the year (probability of hospitalization) and total number of hospital nights.

We do not directly observe the type of pharmaceutical coverage (active individuals under the coinsurance scheme or retired individuals/pensioners exempt from it) of each individual, but this can be inferred from the amount of the retail price borne by the patient. Thus, an individual with positive cost sharing (pharmaceutical cost borne by the patient greater than zero) in all the observed monthly consumptions can be classified as an active individual affected by the coinsurance scheme, while an individual who does not participate in the cost of the drug is identified as a pensioner with free prescription medicines. In addition, we identify individuals who at the beginning of our observational period do participate in the cost of the drug, but from one point in time onwards have zero cost sharing. This last group can be classified as new pensioners who become eligible for exemption from the coinsurance scheme.

The analysis of the effects of the coinsurance exemption on pharmaceutical consumption and hospitalization requires longitudinal information on individuals who change their insurance coverage status during our observational period, as well as on individuals whose coverage remains unchanged. Regarding the new pensioners, we are interested in their pharmaceutical consumption and hospital utilization before and after the change occurs, but the effects on the year in which they become pensioners may be misleading as they will depend on the month in which the transition takes place. Therefore, we restrict the analysis to pharmaceutical consumption in year 2004 and 2006 for individuals who are observed as active and covered by the coinsurance scheme throughout the period, and individuals who retire and become pensioners in 2005 . 
Our final analysis sample corresponds to 88,800 individuals: 22,909 new pensioners who become eligible for coinsurance exemption in 2005, and 65,891 individuals who are active and under the coinsurance scheme in all three periods. In what follows, we will refer to new pensioners as the treatment group, and to active individuals as the control group. In addition, we assess the external validity of our results using a sample of 118,269 individuals who are already pensioners in January 2004 as an additional control group.

\subsection{Empirical strategy}

We aim to identify the effect of copayment exemption on the different outcomes. This could be identified by the parameter $\delta$ in the difference-in-difference model (1) estimated by fixed effects using data for 2004 and 2006, while the change in coverage is identified in 2005.

$$
Y_{i t}=\alpha+\phi C_{i}+\delta L C_{i t}+X_{i t}^{\prime} \beta+\lambda_{t}+u_{i}+\varepsilon_{i t}
$$

where $Y_{i t}$ is the outcome of interest of individual $i$ in year $t, \alpha$ is a constant, $C_{i}$ is a dummy variable that identifies the treatment group; $L C_{i t}$ is a dummy for a decrease in the coinsurance for the treatment group (it combines an indicator of being treated and a dummy for being in the post-treatment period, which is the year 2006 in this case); $X_{i t}$ is the set of covariate explanatory characteristics; $\lambda_{t}$ is a time fixed effect; $u_{i}$ represents the individual fixed unobserved heterogeneity; and $\varepsilon_{\mathrm{it}}$ is a purely random error term. In this model, the effect of the exemption from the coinsurance is identified by $\delta$, which measures the change in pharmaceutical consumption of those with an exemption in their copayment compared to those who remain under the coinsurance.

A potential problem with this approach is the assumption that becoming a pensioner in 2005 is independent of the factors that condition medicine consumption, which is not likely to hold as one would expect individuals who suffer a sudden or even a progressive health deterioration to be more likely to retire and become a pensioner on the one hand, and at the same time increase their pharmaceutical consumption. A selection problem arises if people self-select into retirement based on their health status, $L C_{i t}$ then being correlated with the unobservables. In this situation, the FE estimate of $\delta$ is not consistent. 
We deal with this problem using instrumental variables. Large spikes in the retirement hazards at the earliest retirement age and at the normal retirement age have previously been found in the literature (Gruber and Wise, 2004). In Spain, individuals can first claim old-age benefits at age 60 and the normal retirement age is 65 (Boldrin, Jiménez-Martín and Peracchi, 2004). Therefore, we use the early and full statutory retirement ages to instrument the probability of becoming a new pensioner, as they are expected to have an effect on the probability of retiring while not having an effect on health after controlling for a quadratic age polynomial. We identify the coinsurance effect $\delta$ in equation (1) using instrumental variables fixed effects estimation.

In order to control for changes in the health status of individuals in the treatment and control group we combine health information from two administrative sources. First, we use information from the hospital discharge register. In particular, we can observe the annual number of hospitalizations, the total number of hospital nights, and the annual sum of the weights associated with the diagnosis-related groups.

We also create individual pharmaceutical profiles using the RiskSmart Global Stand Alone application version 2.0 (DxCG, 2005), which builds so-called Aggregated RxGroup (ARXG) categories. ARXGs use detailed information on outpatient claims data on the type of drugs consumed in each period using 18 non-exclusive categories (Zhao et al, 2001; DXCG Inc, 2005). ARXGs have been designed to encompass broad categories of drugs (active ingredients), based upon their most common uses. ARXG categories typically identify the major organ systems with which an agent interacts (e.g., cardiovascular drugs, central nervous system drugs) or the agent's primary pharmacologic activity (e.g., antiinfectives, anti-hyperlipidemics, diabetes drugs). In this paper we use ARXG categories as proxies of treated diagnoses for all individuals. We construct a set of 16 dummies for disease categories, which take value 1 when the individual consumed drugs related to each ARXG category.

The inclusion of ARXG categories in a model that aims to estimate the effect of copayment exemption on pharmaceutical consumption may result in lower estimates if part of the increase due to moral hazard translates into the consumption of a new ARXG category. Therefore, assuming that all the new categories represent new health problems provides a lower bound of the estimate of the impact of copayment exemption on 
pharmaceutical consumption. Thus, we present the results of the models with and without the dummies for ARXG disease categories.

\subsection{Means}

Table 1 presents the means of the outcome variables for each analysis group in 2004 and 2006. The number of DDDs and total pharmaceutical consumption in 2004 is higher among the treatment group, individuals reaching copayment exemption, than for the control group, those who remain active.

Average pharmaceutical expenditure jumped from $€ 296$ in 2004 to $€ 449$ in 2006 (52\% increase) among the treatment group, while it increased by $21 \%$ among the control group (from $€ 262$ in 2004 to $€ 317$ in 2006). Similar differences are observed in the evolution of the average number of DDDs. The cost of the medicines for the public insurer jumped $100 \%$ for people in the treatment group (from €224 in 2004 to $€ 449$ in 2006), but "only" $22 \%$ for control group 1 . This difference is driven not only by higher consumption but also by the effect of providing free drugs for the treatment group in 2006.

In addition, we show means for hospitalizations by age and population group. Both the probability of any hospital stay and the number of hospital nights in 2004 are significantly higher for individuals in the treatment group. This clearly indicates that individuals in the treatment group are more ill than those in the control group and emphasizes the importance of controlling for differences in initial health using fixed effects. Hospital use weighted by diagnosis-related group (DRG) is also $110 \%$ higher for the treatment group in 2004. DRG-weighted hospital use remains higher for the treatment group but the difference has been reduced to $41 \%$ two years later.

Average age is slightly (1.44 years) higher for individuals in the treatment group than for those in the control group. However, we find that some individuals in our sample retire or become pensioners at the age of 59, while others are still employed at the age of 67 . 
Table 1. Means of key outcome variables

\begin{tabular}{|c|c|c|c|c|c|c|}
\hline & \multicolumn{3}{|c|}{2004} & \multicolumn{3}{|c|}{2006} \\
\hline & $\begin{array}{l}\text { Control } \\
\text { group }\end{array}$ & $\begin{array}{l}\text { Treatment } \\
\text { group }\end{array}$ & $\begin{array}{c}\mathrm{p}- \\
\text { value }\end{array}$ & $\begin{array}{l}\text { Control } \\
\text { group }\end{array}$ & $\begin{array}{l}\text { Treatment } \\
\text { group }\end{array}$ & p-value \\
\hline MEDICINES & & & & & & \\
\hline Number of DDDs & 512 & 568 & 0.000 & 650 & 873 & 0.000 \\
\hline Total expenditure $(€)$ & 262 & 296 & 0.000 & 317 & 449 & 0.000 \\
\hline Insurance cost $(€)$ & 198 & 224 & 0.000 & 242 & 449 & 0.000 \\
\hline HOSPITALIZATION & & & & & & \\
\hline Probability of any hospital stay & 0.115 & 0.182 & 0.000 & 0.145 & 0.196 & 0.000 \\
\hline Number of hospital stays & 0.375 & 0.787 & 0.000 & 0.481 & 0.679 & 0.000 \\
\hline COVARIATES & & & & & & \\
\hline Coinsurance & 0.283 & 0.279 & 0.000 & 0.278 & 0 & 0.000 \\
\hline GRDs & 0.144 & 0.270 & 0.000 & 0.199 & 0.282 & 0.000 \\
\hline Age & 58.97 & 61.41 & 0.000 & 61.97 & 63.41 & 0.000 \\
\hline Men & 0.535 & 0.527 & 0.033 & 0.535 & 0.527 & 0.033 \\
\hline Analgesics/anti- & 0.672 & 0.709 & 0.000 & 0.699 & 0.801 & 0.000 \\
\hline inflammatorles & 0.037 & 0.035 & 0.098 & 0.043 & 0.049 & 0.001 \\
\hline Anti-hyperlipidemics & 0.313 & 0.341 & 0.000 & 0.311 & 0.374 & 0.000 \\
\hline Anti-infectives & 0.116 & 0.135 & 0.000 & 0.152 & 0.191 & 0.000 \\
\hline Biologicals & 0.298 & 0.320 & 0.000 & 0.351 & 0.392 & 0.000 \\
\hline Cardiovascular agents & 0.461 & 0.496 & 0.000 & 0.495 & 0.550 & 0.000 \\
\hline Neurological agents & 0.361 & 0.383 & 0.000 & 0.381 & 0.449 & 0.000 \\
\hline Dermatologicals & 0.344 & 0.359 & 0.000 & 0.364 & 0.420 & 0.000 \\
\hline Diabetes drugs & 0.257 & 0.295 & 0.000 & 0.277 & 0.402 & 0.000 \\
\hline Eye, ear, nose, throat preps. & 0.100 & 0.109 & 0.000 & 0.103 & 0.141 & 0.000 \\
\hline Endocrine/metabolic agents & 0.127 & 0.140 & 0.000 & 0.133 & 0.170 & 0.000 \\
\hline Genitourinary agents & 0.288 & 0.329 & 0.000 & 0.353 & 0.467 & 0.000 \\
\hline Gastrointestinal drugs & 0.258 & 0.290 & 0.000 & 0.262 & 0.342 & 0.000 \\
\hline Immunological agents & 0.131 & 0.150 & 0.000 & 0.126 & 0.187 & 0.000 \\
\hline Nutritionals & 0.021 & 0.021 & 0.944 & 0.019 & 0.026 & 0.000 \\
\hline $\begin{array}{l}\text { Pulmonary drugs } \\
\text { Upper respiratory agents }\end{array}$ & 0.025 & 0.029 & 0.001 & 0.023 & 0.029 & 0.000 \\
\hline
\end{tabular}

Note: $\mathrm{p}$-value of Ho: mean $($ control $)=$ mean $($ treated $)$ 


\section{RESULTS}

\subsection{Instrument validity}

The statutory retirement ages can be used as instruments as long as they explain the probability of retiring. Figure 1 in the Appendix shows the retirement hazard as a function of age of the stock sample of individuals who were active in 2004. We see that the hazard of retirement peaks at the ages of 60 and 65 , being highest at the age of 65 .

Table 1A shows the first-stage regression of the probability of retiring in 2005 for our analysis sample with and without controlling for changes in health status. Early statutory retirement age and full retirement age are important predictors of retirement decisions, and we can see that they are jointly highly significant. The probability of retiring increases by 2 percentage points after the early statutory retirement age and by 38 percentage points after the full retirement age. The effect of age is also significant, and it shows the expected quadratic relationship: the probability of being retired is estimated to decrease with age until the age of 61 , and it increases afterwards. On the other hand, we find that a worsening of health status is associated with a higher probability of retirement when health is measured using ARXG diseases, but hospitalizations and GRDs are not significantly associated with retiring. In addition, we estimate the Hansen J-test for each of the models and we do not reject the null hypothesis in all cases ${ }^{2}$.

\subsection{Pooled results}

Cost sharing exemption reduced the average copayment rate for the treatment group from $27.9 \%$ in the year before retirement (2004) to zero in the year after (2006). The causal effects of this exemption on medicine consumption and hospital utilization are shown in Table 2. Each cell reports the estimate of the effect $(\boldsymbol{\delta})$ and its standard error in parentheses.

The second column (Model 1) shows the instrumental variables fixed effects estimates where changes in the health status of the individual are not controlled for. The third

\footnotetext{
${ }^{2}$ Results not shown but available from the authors upon request.
} 
column (Model 2) shows the results controlling for changes in health status ${ }^{3}$. Note that the estimates in Model 2 can be considered as a lower bound of the impact of the exemption on medicine consumption, expenditure and hospital utilization, as any moral hazard effects that lead to the consumption of a new group of drugs are considered as the onset of a health problem.

The results obtained from Model 1 show that on average copayment exemption has a sizeable and highly statistically significant effect on the number of DDDs, amounting to 129.04 DDDs per year per person. Individuals who retired in 2005 consumed on average 873 DDDs. Our estimates suggest that in the same year they would have consumed 744 DDDs without the copayment exemption. Therefore, there is a $17.3 \%$ increase in the number of DDDs that can be associated with the copayment exemption. There is also a high and statistically significant increase in yearly total expenditure per person, $€ 90.0$, which represents a $25 \%$ increase in total pharmaceutical expenditure. Our estimates report an even larger response to the copayment exemption from the insurance cost for the average patient: there is a statistically significant increase of $€ 169.1$ in the cost of pharmaceuticals borne by the public insurer, which accounts for a $60.4 \%$ increase. This extremely large response of the insurance cost to copayment exemption represents the accumulated effect of the reduction of the copayment rate from a maximum of $40 \%$ to zero and the effect of the increase in consumption induced by the policy change.

Once we control for changes in health status (Model 2, shown in the third column of Table 2), we still find a large and significant effect of copayment exemption on medicine consumption and expenditure, although notably lower than those from Model 1. As explained above, we interpret these estimates as a lower bound of the true effect, as any changes in consumption driven by copayment exemption that result in the consumption of medicines from a new group of diseases are considered as a new health problem and not as an effect of the exemption. The results obtained from Model 2 for the average individual also show that copayment exemption results in a highly statistically significant increase of 76.1 DDDs per year per person (a 9.5\% relative increase). Likewise, yearly total expenditure per person increases significantly by $€ 59.4$ (a $15.2 \%$ increase), and total insurance cost by $€ 144.7$ (a $47.5 \%$ increase).

\footnotetext{
${ }^{3}$ We include a quadratic age polynomial in both models. The full set of results is available from the authors upon request.
} 
Table 2. Effects of coinsurance exemption on medicines and hospital utilization

\begin{tabular}{|l|c|c|}
\hline & Model 1 & Model 2 \\
\hline MEDICINES & & \\
- Number of DDDs & $129.90^{* * *}(22.89)$ & $76.09^{* * *}(21.67)$ \\
- Total expenditure $(€)$ & $90.07^{* * *}(14.15)$ & $59.41^{* * *}(13.52)$ \\
- Insurance cost $(€)$ & $169.16^{* * *}(13.77)$ & $144.68^{* * *}(13.23)$ \\
\hline HOSPITALIZATION & $0.009(0.02)$ & $0.000(0.01)$ \\
- Probability of any hospital stay & $-0.097(0.20)$ & $-0.130(0.14)$ \\
- Number of hospital stays & 177,600 & 177,600 \\
\hline Number of observations & & \\
\hline
\end{tabular}

Notes: each column shows coefficients from a different regression; standard errors are reported in parentheses. Column 1 results do not include control for ARXG categories after the intervention. Column 2 results control for ARXG categories after the intervention. *** Denotes significance at the 1 percent level.

The so-called "offset effect" related to reduced patient cost sharing for the elderly could reduce the delay in consumption of prescription medicines or lack of compliance, and result in reduced hospitalizations. Our results in Table 2 clearly indicate that copayment exemption does not significantly reduce the probability of any stay, or the number of hospital nights. Thus, our results do not support the existence of a potential offset or compensating hospital effect of pharmaceutical copayment exemption, in contrast to Chandra et al (2010) and in accordance with the results of the Rand HIE for non-elderly people.

\subsection{Heterogeneity}

We are concerned that coinsurance exemption may have different effects on medicine price sensitivity and hospitalization offsets among different groups of people that may have implications for a more efficient coinsurance design. We explore heterogeneity by the previous coinsurance rate, individual education level, sex, and by the main disease categories. We then run regressions separately by women and men.

As the overall effect of exemption on medicine consumption and expenditure for the average patient is large, the existence of potential heterogeneity in these effects, and also in 
the offset effect, deserves attention in order to derive policy implications for improved copayment designs. We explore the heterogeneity of the effects of the pharmaceutical copayment exemption by the level of the individual copayment rate reduction which the exemption represents, by sex, and by the presence of the main chronic and acute disease categories identified as those individuals treated, classified under any of the 18ARXG disease categories. All heterogeneity effects are estimated using the difference-in-difference model with instrumental variables that control for changes in health status, as in Model 2 in Table 2. We present the results for Model 2 as they can be interpreted as a lower bound of the true effect and the Akaike information criterion favours Model 2 versus Model 1 in all cases $^{4}$.

Table 3 reports the effects of the copayment exemption or free pharmaceuticals for those individuals with a previous average copayment rate lower than $15 \%$, between $15 \%$ and $30 \%$, and above $30 \%$ (with a maximum $40 \%$ rate). Our results show that the effect on the number of DDDs and on total pharmaceutical expenditure is only statistically significant for the group of individuals who had a copayment rate higher than $30 \%$ before retirement. In contrast with most of the previous literature, there is no significant increase in consumption or in expenditure when copayment rates are below 30\% before the copayment exemption. It is important to note that medicines mainly indicated for chronic diseases had a copayment rate below 10\%, and that individuals with an average copayment rate below 30\% were consuming a very high proportion of chronic prescriptions. Results for the average individual with a previous copayment rate above $30 \%$ and no higher than $40 \%$ concentrate the effect of the exemption and show a large and statistically significant increase of 108.4 DDDs per year per person (an 18.5\% increase), and an increase in total pharmaceutical expenditure of $€ 71.4$ per person (a $25.4 \%$ increase). As expected, the exemption from the copayment represents a statistically significant increase in the insurance cost per person of $€ 161.3$ for those individuals who had a copayment rate lower than $15 \%$, €132 for those with average copayment rates between 15 and 30\%, and €121.9 for those with copayment rates higher than 30\% (these represent a $40.4 \%, 32.4 \%$, and $52.9 \%$ relative increase). For the first two groups, the increase in the insurance cost per person after the exemption only captures the effect of the cost shift from the patient to the insurer without any significant consumption increase associated with the copayment

\footnotetext{
${ }^{4}$ Model 1 results for the different subsamples are available from the authors upon request.
} 
reduction. Potential offset effects on hospital utilization are not statistically significant for any of the copayment rate groups.

Table 3. Heterogeneity in effects of coinsurance exemption on medicines and hospital utilization according to coinsurance rate previous to exemption

\begin{tabular}{|l|c|c|c|}
\hline \multirow{2}{*}{} & \multicolumn{3}{|c|}{ Patients with previous coinsurance rate } \\
\cline { 2 - 4 } & $<\mathbf{1 5 \%}$ & $\mathbf{1 5 \%}$ to $\mathbf{3 0} \%$ & $\mathbf{3 0 \%}$ to $\mathbf{4 0} \%$ \\
\hline MEDICINES & $20.03(47.38)$ & $62.15(45.81)$ & $108.44^{* * *}(28.09)$ \\
- Number of DDDs & $62.61(41.69)$ & $37.92(24.99)$ & $71.40^{* * *}(15.11)$ \\
- Total expenditure $(€)$ & $121.85^{* *}(41.10)$ & $131.96^{* * *}(24.37)$ & $161.27^{* * *}(14.94)$ \\
- Insurance cost $(€)$ & & & \\
\hline HOSPITALIZATION & $0.009(0.032)$ & $0.023(0.028)$ & $-0.015(0.017)$ \\
- Probability of any hospital stay & $-0.060(0.357)$ & $-0.164(0.310)$ & $-0.119(0.172)$ \\
- Number of hospital stays & 34,980 & 50,364 & 92,256 \\
\hline Number of observations & & & \\
\hline
\end{tabular}

Notes: each column shows coefficients from a different regression; standard errors are reported in parentheses. Results correspond to models that control for ARXG categories after the intervention. *** Denotes significance at the 1 percent level. ** Denotes significance at the 5 percent level.

Table 4 reports the effects of copayment exemption by sex. Results for the average woman show a higher increase for the number of DDDs and for pharmaceutical expenditure than for the average man. We find a large and statistically significant increase of 117.4 DDDs per year per woman (a 15.4\% relative increase) and a smaller increase of 46.1 DDDs for the average man, which is statistically significant only at $10 \%$ (a $5.6 \%$ increase). There is also a statistically significant increase in the expenditure per woman of $€ 73$, and of $€ 49.7$ for men (a 19.7\% and a 12.3\% increase respectively). Once again, we find that offset effects on hospital utilization are not significant for women or for men. 
Table 4. Heterogeneity in effects of coinsurance exemption on medicines and hospital utilization by gender

\begin{tabular}{|l|c|c|}
\hline & Women & Men \\
\hline MEDICINES & & \\
- Number of DDDs & $117.41^{* * *}(35.29)$ & $46.05^{*}(27.03)$ \\
- Total expenditure (€) & $73.00^{* * *}(20.52)$ & $49.70^{* *}(17.89)$ \\
- Insurance cost (€) & $160.04^{* * *}(20.06)$ & $133.18^{* * *}(17.73)$ \\
\hline HOSPITALIZATION & & \\
- Probability of any hospital stay & $0.001(0.02)$ & $0.001(0.02)$ \\
- Number of hospital stays & $-0.029(0.20)$ & $-0.225(0.21)$ \\
\hline Number of observations & 82,922 & 94,678 \\
\hline
\end{tabular}

Notes: each column shows coefficients from a different regression; standard errors are reported in parentheses. Results correspond to models that control for ARXG categories. *** Denotes significance at the 1 percent level. ${ }^{*}$ Denotes significance at the 5 percent level. * Denotes significance at the 10 percent level.

Table 5 reports the effects of copayment exemption by the 16 ARXG disease categories. Our non-exclusive disease categories are formed by individuals according to the type of pharmaceutical consumption observed in the period before the exemption (year 2004). We run regressions separately for each of the 16 disease groups: analgesics/antiinflammatories, anti-hyperlipidemics, anti-infectives, biologicals, cardiovascular agents, neurological agents, dermatologicals, diabetes drugs, eye, ear, nose and throat preparations, endocrine/metabolic agents, genitourinary agents, gastrointestinal drugs, immunological agents, nutritionals, pulmonary drugs, and upper respiratory agents. We include individual dummy variables for multiple chronic conditions suffered by the same patient to control for co-morbidities. We therefore use a wider and more complete range of chronic and nonchronic diseases than the classifications previously used in the literature on medicine price sensitivity (Chandra et al, 2010; Goldman et al, 2004).

We find that the copayment exemption significantly increases total pharmaceutical expenditure for individuals who before retirement consumed any of the following 11 drug categories: analgesics/anti-inflammatories (€81.4, a 19.9\% increase), anti-infectives (€97.4, a $22 \%$ increase), biologicals (€105.8, a $16.9 \%$ increase), neurological agents (€42, an $8.1 \%$ increase), dermatologicals (€78.6, a $16.7 \%$ increase), diabetes drugs (€81.1, an $18.1 \%$ 
increase), eye, ear, nose and throat preparations (€74.8, a $13.8 \%$ increase), genitourinary agents (€123.9, a 25.1\% increase), gastrointestinal drugs (€80.9, a 16.3\% increase), immunological agents (€106.0, a $21.5 \%$ increase), and pulmonary drugs (€177.3, a $46.5 \%$ increase).

On the other hand, we find no exemption effect on total pharmaceutical expenditure for individuals treated with anti-hyperlipidemics, cardiovascular agents, endocrine/metabolic agents, nutritionals and upper respiratory agents. Once again, we did not find a significant offset hospital effect for most of the disease categories. We only find a slightly significant offset effect for the number of hospital nights of individuals who before retirement consumed immunological agents or endocrine/metabolic agents, a category with a small number of observations, but not for the probability of any stay. Furthermore, we find a significant negative offset (a positive coefficient) for the probability of any stay in individuals treated with upper respiratory agents, indicating that this probability is even higher after copayment exemption. Our results indicate that increased prescription pharmaceutical use does not translate into reduced hospitalization.

Contrary to Chandra et al (2010), who only use a rough dichotomous classification for chronically ill individuals, in a more detailed heterogeneity analysis we find an increase in total pharmaceutical expenditure after copayment exemption not only for consumers of drugs for more acute or less chronic conditions such as analgesics/anti-inflammatories, anti-infectives, dermatologicals and ear, eyes, nose and throat preparations, but also for those treated with pharmaceuticals for chronic conditions or diseases such as diabetes drugs, neurological agents and gastrointestinal agents. It is important to consider that these individuals are treated with medicines indicated for those main chronic conditions, but at the same time they may be treated with medicines indicated for other less chronic or acute conditions. However, previous results indicate that the expenditure effect is not significant for those medicines for chronic conditions charged with a $10 \%$ or lower coinsurance rate before the exemption, which may indicate that the observed effect for individuals with some chronic conditions may be mainly attributed to medicines that are not intended to treat the chronic illness. 
Table 5. Heterogeneity in effects of coinsurance exemption on medicines and hospital utilization by ARXG categories

\begin{tabular}{|c|c|c|c|c|c|c|}
\hline \multirow{2}{*}{ ARXG category } & \multicolumn{3}{|c|}{ MEDICINES } & \multicolumn{2}{|c|}{ HOSPITALIZATION } & \multirow[b]{2}{*}{$\begin{array}{l}\text { Number of } \\
\text { observations }\end{array}$} \\
\hline & DDDs & $\begin{array}{c}\text { Total } \\
\text { expenditu } \\
\text { re }\end{array}$ & $\begin{array}{c}\text { Insurance } \\
\text { costs }\end{array}$ & $\begin{array}{c}\text { Probability of } \\
\text { any stay }\end{array}$ & $\begin{array}{c}\text { Hospital } \\
\text { stays }\end{array}$ & \\
\hline Analgesics/anti-inflammatories & $101.56^{\text {*** }}$ & $81.42^{* * *}$ & $175.92^{* * *}$ & -0.001 & -0.174 & 121,060 \\
\hline Anti-hyperlipidemics & 124.33 & 8.37 & 104.29 & -0.062 & 1.520 & 6,440 \\
\hline Anti-infectives & $89.34^{* *}$ & $97.36^{* *}$ & $190.71 * * *$ & -0.001 & -0.498 & 56,814 \\
\hline Biologicals & 69.09 & $105.81 *$ & $228.13^{* * *}$ & 0.013 & -0.583 & 21,542 \\
\hline Cardiovascular agents & 14.59 & 15.09 & $115.93^{* * *}$ & 0.014 & -0.150 & 53,958 \\
\hline Neurological agents & $70.65^{* *}$ & $42.03^{* *}$ & $141.38^{* * *}$ & 0.023 & -0.115 & 83,466 \\
\hline Dermatologicals & $117.20^{* *}$ & $78.56^{* *}$ & $180.10^{* * *}$ & -0.001 & -0.416 & 65,094 \\
\hline Diabetes drugs & 66.05 & $81.05^{* *}$ & $184.82^{* * *}$ & 0.002 & -0.363 & 61,704 \\
\hline $\begin{array}{l}\text { Eye, ear, nose, throat } \\
\text { preparations }\end{array}$ & 46.03 & $74.79 * *$ & $186.06^{* * *}$ & -0.011 & -0.090 & 47,422 \\
\hline Endocrine/metabolic agents & 70.51 & 77.54 & $186.76^{* *}$ & 0.008 & $-1.148^{*}$ & 18,124 \\
\hline Genitourinary agents & $120.02^{*}$ & $123.85^{* *}$ & $223.64^{* * *}$ & 0.018 & -0.217 & 23,164 \\
\hline Gastrointestinal drugs & $94.07^{* *}$ & $80.89 * *$ & $185.58^{* * *}$ & -0.024 & -0.340 & 52,974 \\
\hline Immunological agents & $113.76^{* *}$ & $105.98^{* * *}$ & $204.38^{* * *}$ & 0.035 & $-0.546^{*}$ & 47,274 \\
\hline Nutritionals & 39.56 & 45.36 & $181.54^{* * *}$ & 0.034 & 0.076 & 24,066 \\
\hline Pulmonary drugs & 34.11 & $177.32 *$ & $283.77 * *$ & 0.025 & -1.191 & 3,680 \\
\hline Upper respiratory agents & 3.36 & 136.59 & $282.18^{* *}$ & $0.200^{* *}$ & 0.245 & 4,572 \\
\hline
\end{tabular}

Notes: each column shows coefficients from a different regression. Results correspond to models that control for ARXG categories. *** Denotes significance at the 1 percent level. ** Denotes significance at the 5 percent level.

\subsection{Arc elasticities}

We estimate individual arc elasticities using the results of the difference-in-difference model with instrumental variables and fixed effects including disease categories after copayment exemption. We then compute the average unweighted arc elasticity and a weighted arc elasticity using expenditure in the before period (year 2004) as individual weights. The results are presented in Table 6 including 95\% confidence intervals for median arc elasticities. Confidence intervals are obtained using 1,000 bootstrapped replications.

The arc elasticity for the median individual is -0.08 , and -0.07 when weighted by expenditure. The median arc elasticities implied by the results of the model without 
controlling by disease categories in the after period are slightly higher: -0.13 and -0.14 respectively.

This arc elasticity for the average individual is similar to the arc elasticities calculated for elderly people by Chandra et al (2010) and to the ones obtained from the Rand HIE for the non-elderly. These results are also similar to those previously obtained from aggregated Spanish cross-section and time series data (Puig-Junoy, 1988). The unweighted median arc elasticity is higher for those individuals with a higher previous coinsurance rate, approximately -0.13 for those who had a copayment rate between $30 \%$ and $40 \%(-0.11$ when the median arc elasticity is weighted). Median arc elasticities for individuals with previous coinsurance rates lower than $15 \%$ or between $15 \%$ and $30 \%$ are lower $(-0.07$ and 0.04 respectively) and only statistically significant at $90 \%$. 
Table 6. Price elasticity for total expenditure on prescribed medicines

\begin{tabular}{|c|c|c|c|c|}
\hline & \multicolumn{2}{|c|}{ Median elasticity } & \multicolumn{2}{|c|}{$95 \%$ confidence interval } \\
\hline & Unweighted & $\begin{array}{l}\text { Expenditure } \\
\text { weighted }\end{array}$ & Unweighted & $\begin{array}{c}\text { Expenditure } \\
\text { weighted }\end{array}$ \\
\hline All patients & $-0.081^{* * *}$ & $-0.068^{* * *}$ & {$[-0.101,-0.048]$} & {$[-0.085,-0.040]$} \\
\hline Coinsurance rates: & & & & \\
\hline$-<5 \%$ & $-0.069^{*}$ & $-0.060^{*}$ & {$[-0.132,0.003]$} & {$[-0.114,0.003]$} \\
\hline$-15 \%$ to $30 \%$ & $-0.042^{*}$ & $-0.036^{*}$ & {$[-0.080,0.005]$} & {$[-0.070,0.004]$} \\
\hline - $>30 \%$ to $40 \%$ & $-0.126^{* * *}$ & $-0.105^{* * *}$ & {$[-0.157,-0.071]$} & {$[-0.130,-0.058]$} \\
\hline Sex: & & & & \\
\hline - Women & $-0.098^{* * *}$ & $-0.085^{* * *}$ & {$[-0.134,-0.051]$} & {$[-0.117,-0.044]$} \\
\hline - Men & $-0.068^{* * *}$ & $-0.056^{* * *}$ & {$[-0.100,-0.024]$} & {$[-0.081,-0.019]$} \\
\hline ARXG categories: & & & & \\
\hline Analgesics/anti-inflammatories & $-0.099^{* k+}$ & $-0.085^{* * *}$ & {$[-0.122,-0.059]$} & {$[-0.105,-0.051]$} \\
\hline Anti-hyperlipidemics & -0.006 & -0.006 & {$[-0.111,0.100]$} & {$[-0.100,0.092]$} \\
\hline Anti-infectives & $-0.109^{* * k}$ & $-0.093^{* * *}$ & {$[-0.149,-0.048]$} & {$[-0.128,-0.041]$} \\
\hline Biologicals & $-0.082^{* *}$ & $-0.076^{* *}$ & {$[-0.151,-0.005]$} & {$[-0.140,-0.005]$} \\
\hline Cardiovascular agents & -0.015 & -0.014 & {$[-0.056,0.024]$} & {$[-0.049,0.021]$} \\
\hline Central nervous system agents & $-0.044^{* *}$ & $-0.040^{* *}$ & {$[-0.077,-0.009]$} & {$[-0.069,-0.008]$} \\
\hline Dermatologicals & $-0.086^{* k *}$ & $-0.075^{* k *}$ & {$[-0.125,-0.034]$} & {$[-0.111,-0.030]$} \\
\hline Diabetes drugs & $-0.078^{* * *}$ & $-0.070^{* * *}$ & {$[-0.112,-0.032]$} & {$[-0.101,-0.029]$} \\
\hline Eye, ear, nose, throat preparations & $-0.084^{* * *}$ & $-0.072^{k+*}$ & {$[-0.128,-0.030]$} & {$[-0.111,-0.026]$} \\
\hline Endocrine/metabolic agents & -0.074 & -0.065 & {$[-0.154,0.023]$} & {$[-0.137,0.020]$} \\
\hline Genitourinary agents & $-0.123^{* *+k}$ & $-0.109^{* * *}$ & {$[-0.192,-0.047]$} & {$[-0.170,-0.041]$} \\
\hline Gastrointestinal drugs & $-0.085^{* * *}$ & $-0.074^{*+*}$ & {$[-0.163,-0.055]$} & {$[-0.152,-0.054]$} \\
\hline Immunological agents & $-0.116^{* k *}$ & $-0.101^{* * *}$ & {$[-0.131,-0.037]$} & {$[-0.143,-0.048]$} \\
\hline Nutritionals & -0.050 & -0.050 & {$[-0.113,0.024]$} & {$[-0.097,0.021]$} \\
\hline Pulmonary drugs & $-0.173^{* *}$ & $-0.152^{* *}$ & {$[-0.333,-0.007]$} & {$[-0.296,-0.006]$} \\
\hline Upper respiratory agents & -0.128 & -0.112 & {$[-0.291,0.044]$} & {$[-0.249,0.038]$} \\
\hline
\end{tabular}

Note: arc elasticities are calculated as $\left(\left(\mathrm{Q}_{2}-\mathrm{Q}_{1}\right) /\left(\mathrm{Q}_{1}+\mathrm{Q}_{2}\right) / 2\right) /\left(\left(\mathrm{P}_{2}-\mathrm{P}_{1}\right) /\left(\mathrm{P}_{1}+\mathrm{P}_{2}\right) / 2\right)$. Arc elasticities have been calculated using the model that controls for ARXG categories. *** Denotes significance at the 1 percent level. ** Denotes significance at the 5 percent level. * Denotes significance at the 10 percent level.

The median arc elasticity is higher for women (-0.10) than for men (-0.07). Arc elasticities are not statistically significant for individuals with ARXG categories such as antihyperlipidemics, cardiovascular agents, endocrine/metabolic agents, nutritionals and upper respiratory agents. Significant median arc elasticities higher than the median for all individuals are observed for individuals in ARXG categories such as pulmonary drugs (0.17), immunological agents (-0.12), genitourinary drugs (-0.12), anti-infectives (-0.11), analgesics/anti-inflammatories (-0.10), dermatologicals (-0.09) and gastrointestinal drugs (0.09). Significant median arc elasticities close to the median for all individuals or lower are 
observed for individuals with ARXG categories such as biologicals (-0.08), diabetes drugs ($0.08)$ and eye, ear, nose and throat preparations $(-0.08)$.

\subsection{External validity}

In the previous section we have used the early and the normal retirement ages to instrument the retirement decision. Therefore, the estimates obtained measure the local average treatment effect (LATE), or the effect of copayment exemption for those individuals who retire because they reach the early retirement age or the normal retirement age.

We are ultimately interested in knowing the effect of copayment exemption on the elderly population, and not only on those who "comply" with the Social Security arrangements. In order to shed some light on the magnitude of this effect, we re-estimate our models without instrumenting for the retirement decision and evaluate how different the effect of copayment exemption is, compared to the effect shown in the previous sections. As before, we show the results for Model 2. In addition, we use a second control group comprising individuals exempted from coinsurance throughout the whole study period because they were already retired in 2004 ( $\mathrm{n}=141,178$ individuals). The results of these additional models are presented in Table 7.

\section{Table 7. External validity}

\begin{tabular}{|l|c|c|}
\hline & $\begin{array}{c}\text { Control group (non- } \\
\text { exempted individuals) }\end{array}$ & $\begin{array}{c}\text { Control group (always } \\
\text { exempted individuals) }\end{array}$ \\
\hline MEDICINES & $117.46^{* * *}(4.30)$ & $67.01^{* * *}(4.68)$ \\
- Number of DDDs & $75.28^{* * *}(3.18)$ & $47.12^{* * *}(3.18)$ \\
- Total expenditure $(€)$ & $162.60^{* * *}(3.06)$ & $119.11^{* * *}(3.14)$ \\
- Insurance cost $(€)$ & 177,600 & 282,356 \\
\hline Number of observations & & \\
\hline
\end{tabular}

Note: *** Denotes significance at the 1 percent level.

All impact estimates shown in Table 7 are significant at 1\% and point to a similar impact to the one in our main results presented in Table 2. The impact of coinsurance exemption when we use the active population as a control group represents an increase of $€ 75.3$ in total pharmaceutical expenditure, which is slightly higher than our estimate for this group 
using instrumental variables. On the other hand, we find a slightly lower estimate when we use those individuals exempted from coinsurance throughout the whole period as a control group. In this case total expenditure is found to increase by $€ 47.1$ because of copayment exemption.

The fact that our previous estimates fall within the range of estimates without controlling for the endogeneity of the retirement decision suggests that they are most likely a good approximation of the average treatment effect.

\section{CONCLUSIONS AND IMPLICATIONS}

Our results show that the uniform exemption from pharmaceutical copayment granted to retired people in Spain has a strong effect on total expenditure on prescription medicines and on insurer cost without an offset effect in the form of reduced hospitalization. Our most conservative estimates show that individuals who were consumers of pharmaceuticals financed by the National Health Service before retirement increase their total pharmaceutical consumption on average by $€ 59.4$ per year, which represents a $15.2 \%$ increase in total pharmaceutical expenditure and a $47.5 \%$ increase in insurer cost. This estimate is a lower bound effect of the expected overall effect, for two reasons. First, our analysis sample is made up of individuals who were buying NHS-prescribed medicines before the copayment exemption. The effect on the subsample of the population that were buying their medicines either without a prescription or with a prescription from a private doctor is expected to be larger, as the change in copayment is from $100 \%$ to $0 \%$ among this group. Second, we use ARXG disease categories to control for changes in health status over time, which results in a lower estimate, as part of the effect may be captured as the onset of a new health problem.

A back-of-the-envelope calculation allows us to estimate the magnitude of the effect on total public pharmaceutical expenditures. In 2006, the last year of our data, there were around 7.8 million pensioners or retired people in Spain. Of the pensioners covered by the NHS, 90.5\% consumed pharmaceuticals prescribed within the public system during 2006. From our estimates, we know that their pharmaceutical consumption was on average $€ 59.4$ higher due to the copayment exemption. This amounts to $€ 463.3$ million, or $4.4 \%$ of total 
pharmaceutical expenditure financed by the NHS. The effect on the amount paid by the insurer is greater than in a situation in which the individuals share part of the cost, as the insurer has to pay the full cost. We know that on average the amount paid by the insurer increased at least €144.68, yielding a total increase in pharmaceutical expenditures of $€ 1,012.76$ million. This magnitude represents $9.7 \%$ of the total pharmaceutical expenditure financed by the NHS.

The effect of copayment exemption is different depending on previous consumption (types of drugs and average copayment rate). We find significant own-price elasticity for the pharmaceutical consumption and expenditure of patients mainly consuming medicines for acute and other non-chronic diseases with a previous coinsurance rate in the range 30 to $40 \%$. The estimated own-price elasticity for this group of patients is -0.13 , which falls within the range of the estimates obtained in the literature and found to be lower when cost sharing changes occur in an NHS (Gemmill et al, 2007). Second, contrary to much of the preceding literature (Baicker and Goldman, 2011), we find that consumption and expenditure of prescription medicines is not significantly price sensitive when free access is obtained by those patients who were previously mainly consuming medicines for chronic conditions under reduced coinsurance rates (no higher than $10 \%$ of the price). In addition, neither is the consumption of those patients who consumed a mix of medicines indicated for both chronic and acute and non-chronic conditions significantly price sensitive. Lastly, unlike some previous studies (Chandra et al, 2010), we did not find a significant offset effect through a decline in hospitalization rates for elderly people exempted from coinsurance rates, which may be explained by the previous low coinsurance rates that affect more ill patients with chronic diseases.

These findings have implications for the design of an optimal coinsurance scheme for prescriptions to elderly and retired people. There is a significant moral hazard effect due to the reduction in the coinsurance rate from $40 \%$ to zero among less sick people without any compensation through a health improvement requiring less hospitalization. At the same time, it seems that a reduced coinsurance rate of around $10 \%$ for medicines mainly prescribed for chronic diseases for elderly people is not a barrier to access pharmaceutical treatment, and does not lead to adverse or negative health effects that could be avoided by granting free prescription medicines. However, there is no case against free medicines or against a $10 \%$ or lower copayment rate for chronic diseases based on the traditional moral 
hazard theory. In our opinion, both implications point to high welfare costs from the indiscriminate exemption granted to elderly and retired people for prescription medicines mainly for non-chronic conditions that were previously affected by the $40 \%$ copayment rate.

Some limitations may affect the results presented in this paper. First, some heterogeneity in patient morbidity may not be perfectly captured by our disease categories or hospitalization use. Second, our estimates measure the short term impact of the zero copayment in the year after exemption but are not able to capture other dynamic effects. Third, heterogeneity in the effects of the exemption which deserve attention may appear in other dimensions not measured in this paper, such as the income level.

Fourth, concurrent changes in the opportunity cost of time of retired people that could influence the demand for physician visits and prescriptions have not been measured and its influence on the consumption effect has not been examined. As long as one assumes that our estimates are also a good approximation of the average treatment effect, the magnitude of the estimate for women could shed some light on the importance of the effect of changes in the opportunity cost of time once retired. A large proportion of women in the age range of this study are inactive and officially obtain coinsurance exemption as dependants of their husbands when they retire. We may presume that the change in the opportunity cost of time should on average be greater for men than for women. We find that the magnitude of the effects is greater for men than for women. This allows at least two non-exclusive interpretations. First, changes in the opportunity cost of time are irrelevant for the subsample of individuals who were already consumers before retirement. And second, pensioners often may be obtaining prescriptions for other household members who are not exempt from copayments (Puig-Junoy, 1988). This second effect is more concentrated among women, and dominates the gender differences in the changes in the cost of time. The likelihood of these assumptions remains a pending research question beyond the scope of this paper.

Finally, as in other studies on cost sharing effects, the increase in consumption associated with zero copayment is compatible with, but is not a proof of, moral hazard (Pita-Barros et al, 2008). 
Future research should explore average and potential heterogeneous cross-price effects of zero copayment for different groups of prescription medicines on emergency visits and office visits. Also, future research should include the careful design of an appropriate experiment of copayment exemption for retired people using retired civil servants covered by a health plan with a 30\% pharmaceutical copayment as a control group. Our results allow the development of micro-simulation models to accurately predict the expected impact of reforms in the prevailing Spanish copayment scheme for prescription medicines. 


\section{REFERENCES}

- Atella V, Peracchi F, Depalo D, Rossetti C, 2006. Drug compliance, co-payment and health outcomes: Evidence from a panel of Italian patients. Health Economics 15, 875-892.

- Baicker K, Goldman D, 2011. Patient cost-sharing and healthcare spending growth. Journal of Economic Perspectives 25, 47-68.

- Boldrin M, Jiménez-Martín S, Peracchi F, 2004. Micro-Modeling of Retirement Behavior in Spain. In: Jonathan Gruber and David A. Wise, editors. Social Security Programs and Retirement around the World: Micro-Estimation, University of Chicago Press.

- Costa Font J, Puig-Junoy J, 2007. Institutional change, innovation and regulation failure: evidence from the Spanish drug market. Policy \& Politics 35, 701-718.

- DXCG Inc. DxCG ${ }^{\circledR}$ RiskSmart ${ }^{\mathrm{TM}}$ Stand Alone, 2005. User guide. Version 2.0.

- Gemmill MC, Costa-Font J, McGuire A, 2007. In search of a corrected prescription drug elasticity estimate: a meta-regression approach. Health Economics 16, 627-643.

- Goldman DP et al, 2004. Pharmacy benefits and the use of drugs by the chronically ill. Journal of the American Medical Association 291, 2344-2350.

- Goldman DP, Joyce GF, Zheng Y, 2007. Prescription drug cost sharing: Associations with medication and medical utilization and spending and health. JAMA 298, 61-69.

- Grootendorst PV, 1997. Health care policy evaluation using longitudinal insurance claims data: an application of the panel Tobit estimator. Health Economics 6, 365-382.

- Leibowitz A, Manning WG, Newhouse J, 1987. The demand for prescription drugs as a function of cost-sharing. Social Science and Medicine 21, 1063-1069.

- Manning WG et al, 1997. Health insurance and the demand for medical care: evidence from a randomized experiment. American Economic Review 77, 251-277.

- Newhouse J, 1993. Free for all: Lessons from the RAND Health Insurance Experiment. Cambridge MA, Harvard University Press.

- OECD, 2010. Health at a glance: Europe 2010. OECD Publishing.

- Paris V, Devaux M, Wei L, 2010. Health systems institutional characteristics: A survey of 29 OECD countries. OECD Health Working Papers; No. 50, OECD Publishing.

- Pita-Barros P, Machado MP, Sanz-de-Galdeano A, 2008. Moral hazard and the demand for health services: A matching estimator approach. Journal of Health Economics 27, 1006-1025. 
- Puig-Junoy J, 1988. Gasto farmacéutico en España: efectos de la participación del usuario en el coste. Investigaciones Económicas 12, 45-68.

- Rice T, Matsuoka KY, 2004. The impact of cost-sharing on appropriate utilization and health status: A review of the literature on seniors. Medical Care Research and Review 61, 415-452.

- Scherer P, Devaux M, 2010. The challenge of financing health care in the current crisis: An analysis based on the OECD data. OECD Health Working Papers; No. 49, OECD Publishing.

- Zhao Y et al, 2001. Measuring population health risks using inpatient diagnoses and outpatient pharmacy data. Health Services Research 36, 180-193. 


\section{APPENDIX}

Figure 1. Retirement hazard

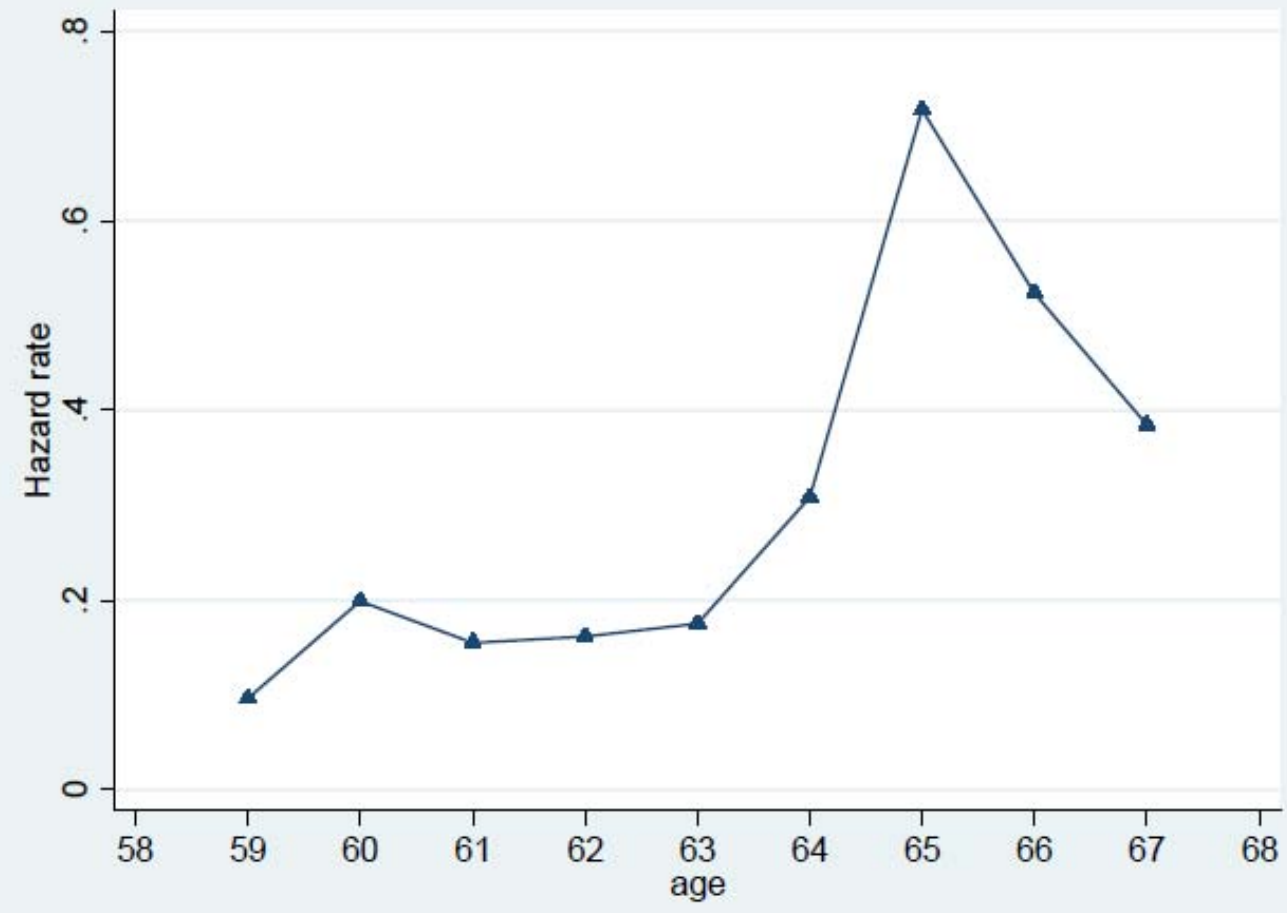


Table A1. First stage results

\begin{tabular}{|c|c|c|}
\hline & Model 1 & Model 2 \\
\hline Over early retirement age & $0.021 * * *(0.003)$ & $0.024 * * *(0.003)$ \\
\hline Over full retirement age & $0.386^{* * *}(0.007)$ & $0.380 * * *(0.007)$ \\
\hline Age & $-0.075^{* *}(0.031)$ & $-0.071 * *(0.031)$ \\
\hline $\mathrm{Age}^{2}$ & $0.012^{* * *}(0.000)$ & $0.012^{* * *}(0.000)$ \\
\hline Year 2006 & $0.201 * * *(0.062)$ & $0.188^{* *}(0.062)$ \\
\hline Analgesics & & $0.027 * * *(0.003)$ \\
\hline Anti-hyperlipidemics & & $0.036^{* * *}(0.007)$ \\
\hline Anti-infectives & & $0.003(0.002)$ \\
\hline Biologicals & & $0.019 * * *(0.005)$ \\
\hline Cardiovasculars agents & & $0.014 * * *(0.004)$ \\
\hline Central nervous system agents & & $0.007 * *(0.003)$ \\
\hline Dermatologicals & & $0.016^{* * *}(0.003)$ \\
\hline $\begin{array}{l}\text { Eye, ear, nose, throat } \\
\text { preparations }\end{array}$ & & $0.042^{* * *}(0.003)$ \\
\hline Endocrine/metabolic agents & & $0.017 * * *(0.004)$ \\
\hline Diabetes drugs & & $0.030 * * *(0.003)$ \\
\hline Pulmonary drugs & & $0.020 * *(0.008)$ \\
\hline Gastrointestinal drugs & & $0.030^{* * *}(0.003)$ \\
\hline Genitourinary agents & & $0.019 * * *(0.004)$ \\
\hline Immunological agents & & $0.016^{* * *}(0.003)$ \\
\hline Nutritionals & & $0.028^{* * *}(0.003)$ \\
\hline Upper respiratory agents & & $0.003(0.007)$ \\
\hline Hospital stay & & $-0.001(0.003)$ \\
\hline Number of hospital nights & & $-0.003^{* * *}(0.001)$ \\
\hline GRDs & & $-0.001(0.002)$ \\
\hline Number of observations & 177,600 & 177,600 \\
\hline F-test & $1712.57($ Prob $>F=0.000)$ & $1676.07($ Prob $>F=0.000)$ \\
\hline
\end{tabular}

Notes: ${ }^{* *}$ Denotes significance at the 1 percent level. ${ }^{* *}$ Denotes significance at the 5 percent level. 